\title{
DECREASED GLUTAMATE UPTAKE IN SUBCORTICAL AREAS DEAFFERENTED BY SENSORIMOTOR CORTICAL ABLATION IN THE CAT ${ }^{1}$
}

ANNE B. YOUNG, MARK B. BROMBERG, AND JOHN B. PENNEY, JR.

University of Michigan, Department of Neurology, Ann Arbor, Michigan 48109

\begin{abstract}
Evidence that L-glutamate is a neurotransmitter of corticofugal fibers was sought by measuring changes in several biochemical markers of neurotransmitter function after pericruciate (sensorimotor) ablations in cats. Two weeks after cortical ablation, samples from various brain regions were analyzed for high affinity uptake of glutamate, $\gamma$-aminobutyric acid (GABA), glycine, alanine, and tyrosine. Amino acid levels and the activity of choline acetyltransferase (CAT) also were determined. High affinity glutamate uptake is decreased relative to the opposite side in areas of the nervous system which lost a predominantly unilateral corticofugal projection. These areas include the caudate nucleus, ventrolateral thalamic nucleus, red nucleus, basis pontis, and cervical and lumbar spinal cord. No significant changes were found in the uptake of other amino acids or in CAT in these regions. Changes in the levels of amino acids were significant only in ventrolateral thalamus where there was a $33 \%$ decrease in glutamate on the deafferented side. The data suggest that L-glutamate is a neurotransmitter of corticofugal fibers to many subcortical areas related to motor control.
\end{abstract}

The role of the cerebral cortex in motor control increases in importance as one ascends the phylogenetic scale and cortical fiber projections have been studied in detail. Cortical influences on motoneurons involve two nearly parallel fiber systems. The lateral corticospinal tract is a direct pathway to the spinal cord and thence to motoneurons, while the corticobulbar tract is the first part of an indirect and more integrative corticospinal pathway involving brain stem relay neurons which in turn continue to the spinal cord as subcortical descending tracts (Lawrence and Kuypers, 1968; Shapovalov, 1975). Thus, lesions of the cerebral cortex or of its fibers affect motoneurons in the spinal cord and lead both directly and indirectly to impairment of fine motor control and spasticity in humans (Fisher and Curry, 1965; Ropper et al., 1979). Although the anatomy of corticofugal pathways has been mapped and their synaptic actions have been examined in detail, the neurotransmitter(s) liberated from cortical terminals have been studied only recently. Identification and characterization of the cortical neurotransmitter and its metabolism will increase our understanding of normal motor control as well as the abnormalities of motor function seen in diseases affecting

\footnotetext{
${ }^{1}$ This work was supported by United Cerebral Palsy Research and Education Foundation Grants R-310-78 and R-305-79, Grants NS0046401, NS00420-01, and NS15140-02, the Committee to Combat Huntington's Disease, and the Michigan Memorial Phoenix Project. We wish to thank Patricia Blackman, Francis Hospod, Joseph Robertson, Michael Sepanski, and Barbara Stephenson.
}

corticofugal pathways, such as cerebral palsy, stroke, multiple sclerosis, and spinal cord trauma.

In recent investigations of the neurotransmitter of corticofugal fibers, a variety of electrophysiological, histochemical, and biochemical techniques were used to study putative excitatory neurotransmitters in areas of the nervous system receiving cortical fiber terminals. The excitatory amino acid, L-glutamate, is the most likely candidate (Stone, 1973, 1976, 1979; Davis and Vaughan, 1969; Altmann et al., 1976; Fonnum, 1978; Bromberg et al., 1980). Previously, we studied neurotransmitter amino acids in two areas of rat brain and found a decrease in the high affinity uptake of L-glutamate in the ventrolateral nucleus of thalamus and red nucleus after ablation of sensorimotor cortex (Bromberg et al., 1980). This decrease in uptake is accompanied by a selective decrease in glutamate levels in the ventrolateral nucleus of thalamus without a change in aspartate levels. In the present study in the cat, we have sought further evidence favoring glutamate as the neurotransmitter mediating excitation at corticofugal terminals. We have measured the high affinity uptake and concentration of several putative amino acid neurotransmitters as well as the activity of choline acetyltransferase (CAT) in a large number of nuclei along the corticofugal projection pathway after removal of the sensorimotor (pericruciate) cortex.

\section{Materials and Methods}

Adult cats ( 3 to $4 \mathrm{~kg}$ ) were anesthetized with ketamine and, under sterile conditions, received a unilateral abla- 
tion of the pericruciate cortex. The anterior and posterior ectosylvian gyri and the coronal gyrus were removed by suction. After a 14-day survival period, the animals were reanesthetized with ketamine and the calvarium was removed while keeping the dura intact. The spinal cord then was transected at the $C_{1}$ segment and the brain was removed rapidly and placed in $4^{\circ} \mathrm{C} 0.32 \mathrm{M}$ buffered sucrose solution. A complete laminectomy was performed and the cord also was placed in cold sucrose solution. The interval from cord transection (and decreased brain and spinal cord perfusion) to removal of the brain took 8 to $10 \mathrm{~min}$ and an additional $15 \mathrm{~min}$ was required to remove the spinal cord. In a $4^{\circ} \mathrm{C}$ environment, the brain and spinal cord were cut in the coronal plane into $2-\mathrm{mm}$ thick sections. Under a dissecting microscope, 14 gauge hypodermic tubing ( $1.6 \mathrm{~mm} \mathrm{ID)} \mathrm{was} \mathrm{used} \mathrm{as} \mathrm{a} \mathrm{punch} \mathrm{to}$ remove tissue bilaterally from caudate nucleus, ventrolateral nucleus of thalamus, red nucleus, pontine nuclei, dorsal column nuclei, medullary reticular formation, cerebellar cortex, and the central gray matter of cervical, thoracic, and lumbar spinal cord (see Fig. 1). The tissue samples $(1.0$ to $5.0 \mathrm{mg})$ were placed either in tubes containing $1 \mathrm{ml}$ of cold $0.32 \mathrm{M}$ buffered sucrose solution or on foil and then frozen over dry ice and stored at $-70^{\circ} \mathrm{C}$. Sections containing the ablation site and the punch sites were fixed in $10 \%$ buffered formalin solution.

Amino acid uptake. The tissue punches, in $1 \mathrm{ml}$ of cold $0.32 \mathrm{M}$ buffered sucrose solution, were homogenized in a Potter-Elvehjem homogenizer fitted with a Teflon pestle, diluted 5-fold with ice cold sucrose, and spun at 20,000 $\times g$ for $20 \mathrm{~min}$. The resultant supernatant was discarded and the pellet ( $P_{1}$ and $P_{2}$ combined) was resuspended in cold $0.32 \mathrm{M}$ buffered sucrose. Determination of high affinity uptake of tritrated L-amino-acids (20 to $60 \mathrm{Ci} / \mathrm{mmol}$, Amersham/Searle Corp.) were performed subsequently as previously described (Young et al., 1974). The pellets were solubilized with $0.5 \mathrm{ml}$ of NCS solubilizer (Amersham/Searle Corp.). Six milliliters of OCS (Amersham/ Searle Corp.) was added to each tube, the samples were transferred to Beckman Minivials, and the radioactivity was determined by liquid scintillation spectrometry (Beckman LS 8100, efficiency 38\%). Under these conditions, amino acid uptake is linear with tissue and time, less than $10 \%$ of the added substrate is accumulated, and uptake is predominantly into the synaptosomal fraction. Proteins were measured by the method of Lowry et al. (1951).

CAT assay. Choline acetyltransferase (CAT) (EC 2.3.1.6) was measured as previously described using homogenates of tissue treated with Triton X-100 (final concentration, $0.5 \% \mathrm{v} / \mathrm{v})$ and $\left[1-{ }^{14} \mathrm{C}\right]$ acetylcoenzyme A (Amersham/Searle Corp.) (Fonnum, 1975).

Amino acid levels. Amino acid levels were determined by high pressure liquid chromatographic (HPLC) separation of their ortho-phthaldialdehyde (OPA) derivatives. Tissue samples from various regions were weighed and homogenized in $500 \mu \mathrm{l}$ of cold $70 \%$ ethanol and allowed to stand for at least $3 \mathrm{hr}$ before centrifugation in a Beckman microfuge. Twenty-microliter aliquots of supernatant were derivatized with $120 \mu \mathrm{l}$ of OPA reagent, allowed to react for $75 \mathrm{sec}$, and then passed through the chromatograph. The aqueous eluent (A), $0.1 \mathrm{~m}$ sodium acetate (Baker) at $\mathrm{pH}$ 5.5, was filtered and degassed before use. The organic modifier (B) was methanol (HPLC grade, Baker).

Analyses were performed at room temperature with dual Altex model 110A pumps, an Altex 420 programmable gradient maker, a Valco model CV-6-UHPa-N60 injection valve, a Schoeffel FS 970 L.C. fluorimeter (excitation wavelength, $330 \mathrm{~nm}$ and a 418-nm cut-off filter), a Linear Instruments model 585 recorder, and a Brownlee Labs Spheri-5A $\left(5-\mu \mathrm{m}, \mathrm{C}_{18}\right)$ reverse phase column. Flow rate was $0.7 \mathrm{ml} / \mathrm{min}$ and the sample was chromatographed isocratically at $35 \% \mathrm{~B}$ in A for $6 \mathrm{~min}$ followed by a gradient to $70 \% \mathrm{~B}$ over $8 \mathrm{~min}$. The $70 \% \mathrm{~B}$ was maintained for 3 min and then brought back to $35 \%$ B over 5 min. This method separates most conventional amino acids and clearly separates all putative neurotransmitter amino acids except proline which is not derivatized by OPA. This technique is a modification of previously described methods (Hodgin, 1979; Lindroth and Mopper, 1979).

Histology. One cat received a unilateral cortical ablation and was perfused 5 days later with buffered formalin. The brain was removed and serial $25-\mu \mathrm{m}$ frozen sections were cut and stained for degenerating fibers and axon terminals by the method of Fink and Heimer (1967). The sections were examined with a light microscope to determine the pattern of degenerating axon terminals in striatum, thalamus, red nucleus, pons, medulla, and spinal cord.

Serial $25-\mu \mathrm{m}$ frozen sections also were cut from the formalin-fixed tissues of the animals used for neurochemical studies and representative sections were stained with cresyl violet. These were examined to determine the extent of the ablation and the location of the punch sites. In all cases, the ablation site was confined to the pericruciate cortex. All biochemical values from punches in the areas indicated in Figure 1 were included in subsequent analysis.

\section{Results}

The sections stained by the Fink-Heimer (1967) method were examined to determine the distribution of degenerating terminals in the feline central nervous system after unilateral pericruciate ablation. Figure 1 shows a series of coronal section drawings with pairs of photomicrographs of tissue stained for degenerating fibers from regions indicated by the circles (right side of figure is ipsilateral to the ablation and left side is contralateral). The circles also mark sites from which tissue was taken for biochemical analyses.

The distribution of degenerating terminals is consistent with previous studies involving various frontal lobe ablations (Brodal, 1968; Kuypers, 1958, 1964; Kuypers and Tuerk, 1964). There were bundles of degenerating axons ipsilateral to the ablation in the corpus callosum, internal capsule, crus cerebri, basis pontis, and medullary pyramid and bundles contralateral in the lateral columns of the spinal cord. Numerous degenerating axons left the main fiber bundles to enter the ipsilateral retrothalamic fasciculus (Ramon-Moliner, 1979). Axons entered the reticular formation of the midbrain, pons, and medulla bilaterally and spinal gray matter contralat- 
erally. Fields of degenerating axon terminals were observed bilaterally in the caudate nucleus and putamen, but the ipsilateral fields were more dense (Fig. $1 B$ ). The ventral tier of the thalamus (ventral anterior, ventral lateral, ventral medial, and ventral posterior nuclei) contained degenerating terminals ipsilateral to the ablation (Fig. 1C). The pontine nuclei on the ipsilateral side showed a dense array of degenerating terminals (Fig. $1 E)$. Terminals mixed with fibers were present in the ipsilateral red nucleus (Fig. $1 D$ ). The medullary reticular formation (Fig. $1 F$ ) and dorsal column nuclei, mostly cuneate nucleus (Fig. $1 G$ ), showed a bilateral distribution of degenerating fibers and terminals. Degenerating terminals in the spinal cord (Fig. $1, H$ to $J$ ) were observed in Rexed's laminae III to VII contralateral to the ablation. The cervical and lumbar enlargements displayed a greater density of degenerating terminals than did the thoracic segments.

The high affinity uptake of L-glutamate was measured in washed crude homogenates of tissue samples taken bilaterally from 10 regions of the cat brain 14 days after unilateral pericruciate lesions. The histogram in Figure 2 demonstrates the differences in uptake levels between the lesioned and the intact side of the animals expressed as a relative percentage of the intact side. The data represent the average of values from four to five animals. Thus, the ventrolateral nucleus of the thalamus ipsilateral to the cortical lesion shows a $45 \%$ reduction compared to the contralateral side, while the anterior horn of the lumbar cord shows a 30\% increase in the ipsilateral side with respect to the opposite side. In lumbar cord, the ipsilateral side is the physiologically normal side and the contralateral side contains degenerating terminals. The data are displayed in Figure 2 as the percentage of difference relative to the side contralateral to the cortical ablation (intact side) to show that the distribution of negative and positive differences in the histogram parallels the laterality of the distribution of corticofugal fiber terminals displayed in Figure 1. The differences in uptake levels between the two sides were analyzed by a onetailed paired $t$ test and there is a significant $(p<0.05)$ reduction in the uptake of glutamate in the caudate, thalamus, red nucleus, and pons which are areas receiving an ipsilateral pericruciate projection. The medullary reticular formation also shows a reduction ipsilateral to the cortical ablation, but it is not significant, due probably to the bilaterality of the projection to that area. Glutamate uptake in the dorsal column nuclei (primarily cuneate nucleus) ipsilateral to the lesion is essentially no different from the contralateral side, again presumably reflecting the bilaterality of the pericruciate projection. The cerebellar cortex served as a control site since no corticofugal fibers project there directly and glutamate uptake is identical on both sides. The corticospinal tract is crossed and, accordingly, tissue from the central gray matter of both the cervical and lumbar enlargements shows significant reductions in glutamate uptake, while in the thoracic cord, the change is not significant because the density of degenerating fibers is lowest in that section of the cord.

Table I displays the values used to construct the histogram in Figure 2. Column $\mathrm{A}$ lists the uptake of L$\left[{ }^{3} \mathrm{H}\right]$ glutamate on the intact side (defined here as the side contralateral to the cortical ablation despite known degeneration in spinal cord on this side secondary to decussation of the tract) and column $B$ lists the mean \pm SEM of the differences between the two sides in four to five animals. The data also have been recalculated in column $\mathrm{C}$ using as the control side the side of the animal receiving the least cortical input. This ratio reflects the percentage of decrease in glutamate uptake caused by the loss of corticofugal terminals at each level.

In order to determine whether this decrease in glutamate uptake is a nonspecific change seen in degenerating terminals, we measured changes in the high affinity uptake of several amino acids in the six sites of brain and spinal cord which demonstrated a significant reduction in glutamate uptake. The high affinity uptake (at $10^{-6} \mathrm{M}$ ) of glycine and $\gamma$-aminobutyric acid (GABA) were measured in three of these regions and the uptakes of alanine and tyrosine were determined in the remaining three areas (Table II, columns A and B). The ratios of uptake on the side of the cortical ablation to that on the contralateral side were not significantly different in any region by paired $t$ test (column D). None of the differences between intact and lesioned sides have a distribution similar to the differences in glutamate uptake which match the crossing of the corticospinal tract. Thus, it is unlikely that the changes in glutamate uptake represent a nonspecific change. We also measured the activity of CAT, the rate-limiting enzyme in the synthesis of acetylcholine, in five of the six areas which had reductions in the high affinity uptake of glutamate (Table III). There are significant reductions in CAT activity ipsilateral to the lesion in caudate and pons, and a minimally significant reduction ipsilateral to the lesion in lumbar spinal cord, but these do not parallel the distribution of the corticospinal tract.

Figure $1 .{ }^{2}$ Pattern of degeneration (Fink-Heimer (1967) technique) at various levels of the neuraxis after unilateral pericruciate ablation in cat. $A$, Ablation site. $B$ to $J$, Middle, coronal section line drawings showing punch sites from which tissue was taken for analysis (circles) and pattern of degenerating corticofugal fibers (stippling); left, photomicrographs of tissue stained by the Fink-Heimer technique from region of circles contralateral to the ablation (right side of animal); right, photomicrographs of similarly stained tissue ipsilateral to the ablation (left side of animal). $B$, Caudate nucleus; $C$, ventrolateral nucleus of thalamus; $D$, red nucleus; $E$, pontine nuclei; $F$, medullary reticular formation; $G$, cuneate nucleus; $H$, cervical cord; $I$, thoracic cord; $J$, lumbar cord.

\footnotetext{
${ }^{2}$ The abbreviations used on the figures and in the tables are: BP, basis pedunculi; CAUD, caudate; CBL, cerebellar lesion; CSC, cervical spinal cord; DCN, dorsal column nuclei; IC, internal capsule; LC, lateral column; LSC, lumbar spinal cord; MRF, medullary reticular formation;

P, putamen; PYR, medullary pyramid; RN, red nucleus; TSC, thoracic spinal cord; VL, ventral lateral nucleus; VPL, ventral posterolateral nucleus; VPM, ventral posteromedial nucleus.
} 


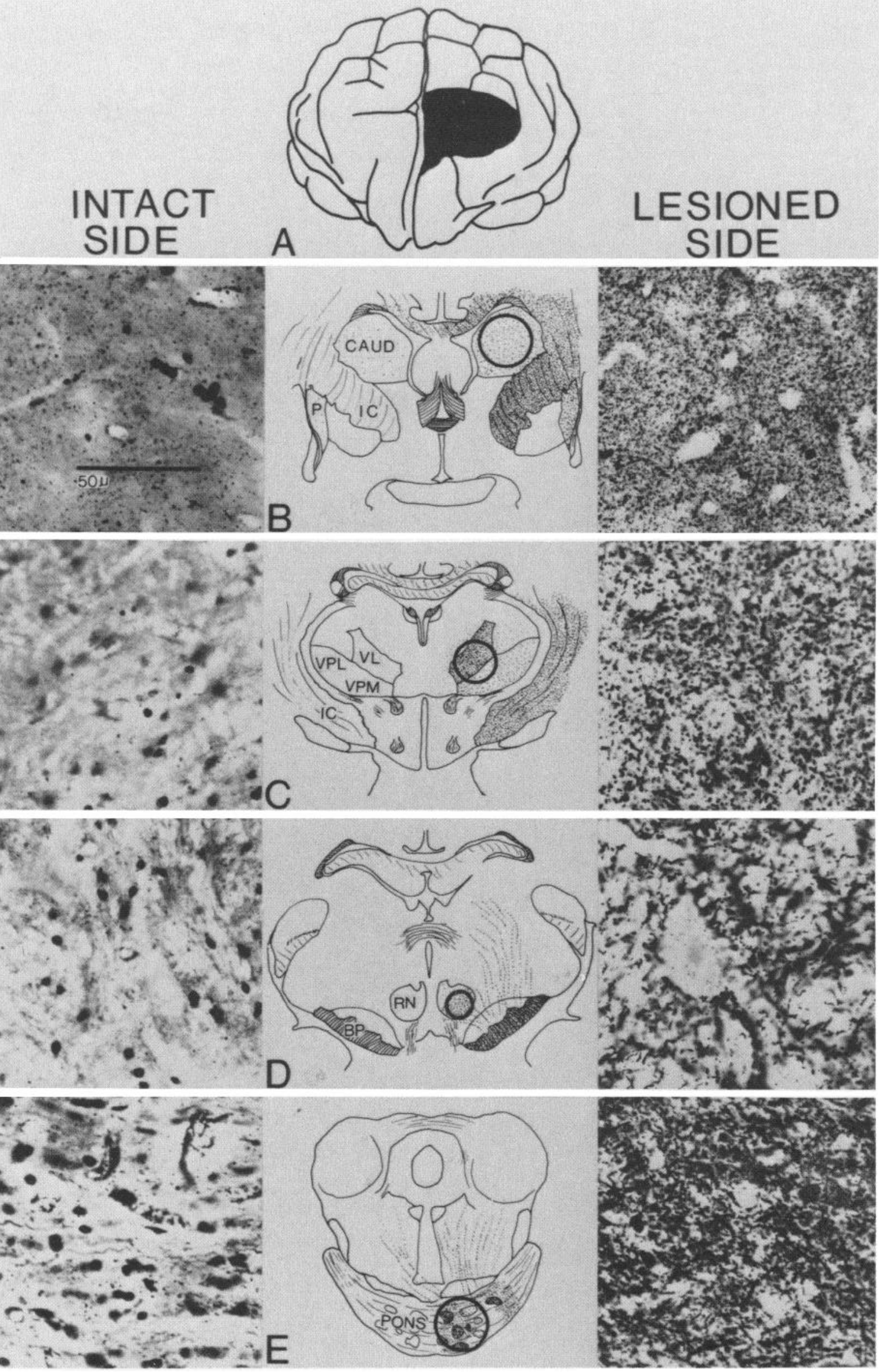




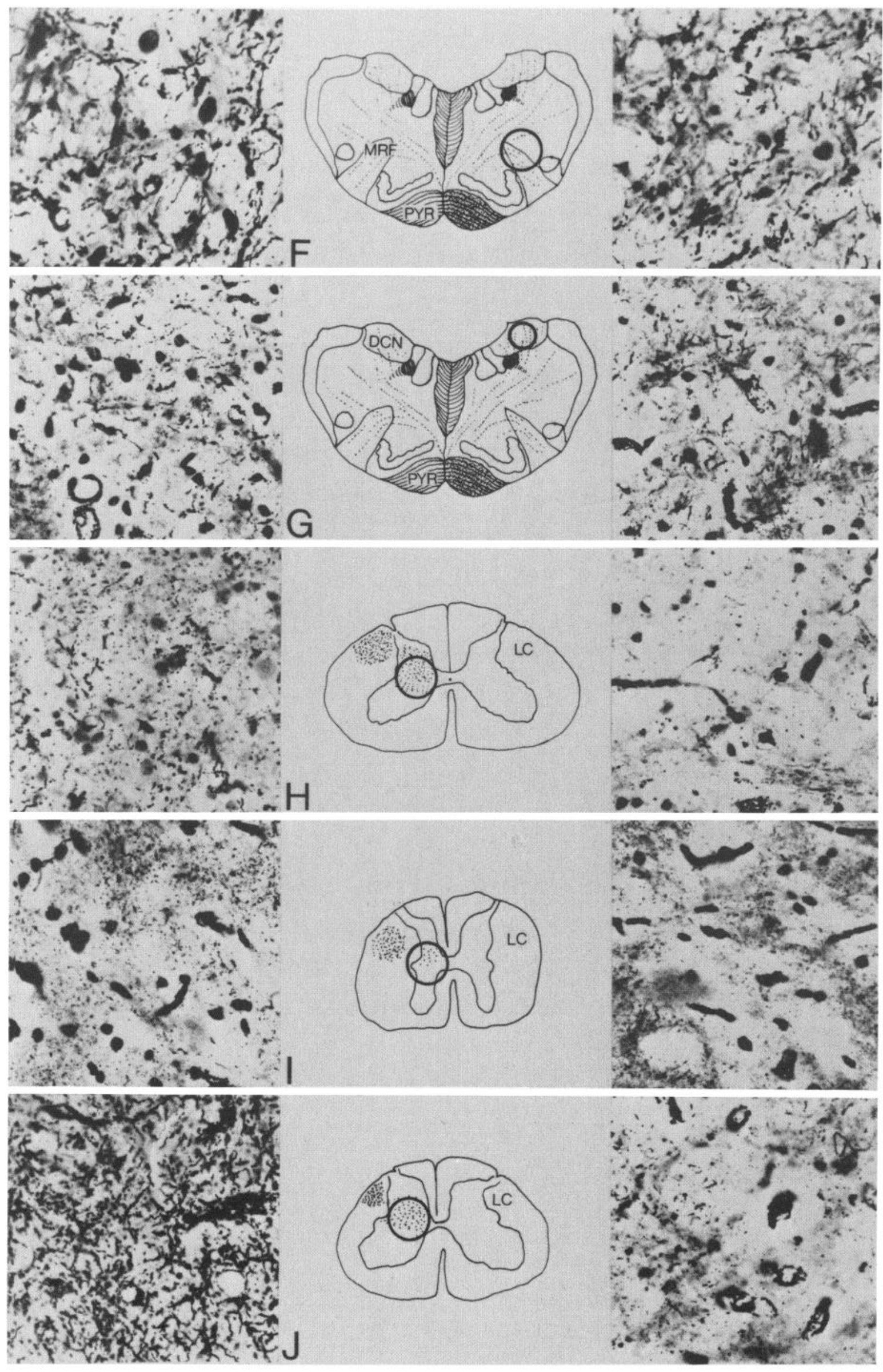




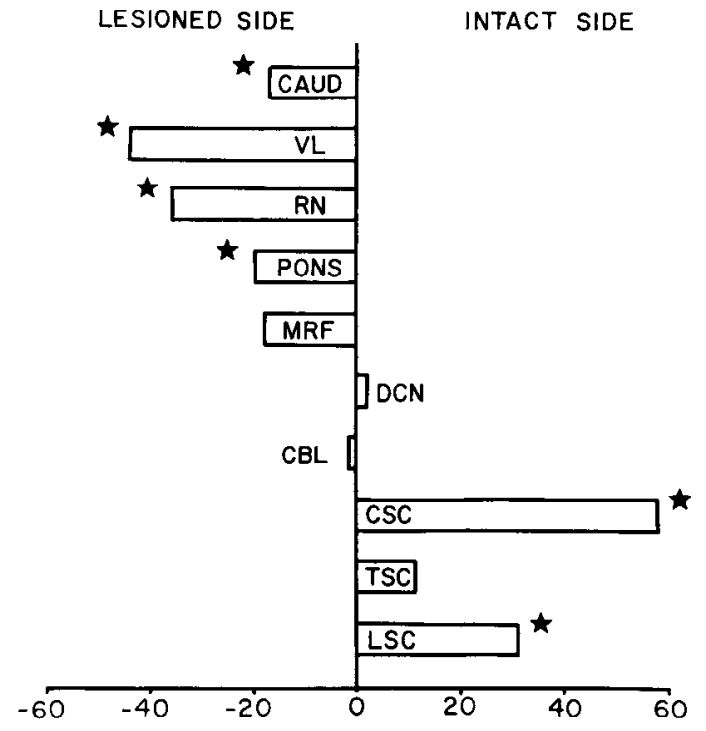

PERCENT DIFFERENCE FROM INTACT SIDE

Figure 2. Histogram of percentage change in high affinity Lglutamate uptake at various levels of the nervous system. Lesioned side is defined as the side of the neuraxis ipsilateral to the pericruciate ablation. Thus, the histogram bars change direction in the spinal cord because the corticospinal tract decussates. Abscissa: (uptake on lesioned side - uptake on intact side/uptake on intact side) $\times 100$. See text for discussion. Ordinate: sites of tissue samples. Numbers are averaged glutamate uptake values from five animals. Stars indicate significance at $p<0.05$ (paired one-tailed $t$ test).

TABLE I

$\mathrm{L}$-Glutamate uptake in various regions of cat central nervous system after unilateral pericruciate cortex ablations

\begin{tabular}{|c|c|c|c|c|}
\hline \multirow[b]{2}{*}{ Region } & Column $\mathrm{A}^{a}$ & Column $\mathrm{B}^{b}$ & Column $\mathrm{C}^{c}$ & \multirow[b]{2}{*}{$\begin{array}{c}\text { No. } \\
\text { of } \\
\text { Animals }\end{array}$} \\
\hline & $\begin{array}{l}\text { L-Glutamate } \\
\text { Uptake } \\
\text { Intact Side }^{d}\end{array}$ & $\begin{array}{l}\text { Mean Differences } \\
\text { Intact - Lesioned } \\
\text { Side }\end{array}$ & $\begin{array}{l}\text { L-Glutamate } \\
\text { Uptake } \\
\text { Degenerated } \\
\text { Side }^{e} \\
\text { as \% Control } \\
\text { Side }\end{array}$ & \\
\hline & \multicolumn{2}{|c|}{$\mathrm{pmol} / 5 \mathrm{~min} / \mathrm{mg}$ protein $(S E M)$} & $\%$ & \\
\hline Caudate & $181 \pm 14$ & $34 \pm 17^{\prime}$ & 83 & 5 \\
\hline VL & $249 \pm 31$ & $111 \pm 29^{f}$ & 56 & 5 \\
\hline $\mathbf{R N}$ & $46 \pm 4$ & $17 \pm 8^{f}$ & 64 & 5 \\
\hline Pons & $40 \pm 12$ & $8.2 \pm 3.7^{f}$ & 80 & 5 \\
\hline MRF & $18 \pm 4$ & $4.9 \pm 3.6$ & 82 & 4 \\
\hline DCN & $17 \pm 2$ & $0 \pm 6.4$ & 98 & 5 \\
\hline CBL & $38 \pm 5$ & $0.7 \pm 1.0$ & & 5 \\
\hline $\mathrm{CSC}$ & $16 \pm 3$ & $-13.5 \pm 6.1^{f}$ & 63 & 4 \\
\hline TSC & $20 \pm 6$ & $-3.3 \pm 6.7$ & 90 & 4 \\
\hline LSC & $20 \pm 2$ & $-6.1 \pm 2.5^{f}$ & 76 & 5 \\
\hline
\end{tabular}

${ }^{a}$ Column A, mean L-glutamate uptake \pm SEM in each region. Uptake was determined at $10^{-7} \mathrm{M} \mathrm{L}-\left[{ }^{3} \mathrm{H}\right]$ glutamate concentration.

${ }^{b}$ Column $B$, mean \pm SEM of the differences between the intact and lesioned side in each region. Values were used to calculate significance in the paired $t$ test.

${ }^{c}$ Column C, L-glutamate uptake on the side with degenerating terminals as a percentage of the nondegenerating side.

d Intact side is the side contralateral to cortical ablation.

${ }^{e}$ Degenerated side is the side with the predominance of degenerating fibers (see Fig. 1).

${ }^{f}$ Significant at $p<0.05$ by paired one-tailed $t$ test.
There is evidence that glutamate and aspartate share a common high affinity uptake mechanism (Balcar and Johnston, 1972; Snyder et al., 1973). To distinguish between the two (and other amino acids) as possible neurotransmitters, we measured the change in levels of six amino acids in 10 regions by HPLC techniques. The results of the amino acid determinations in the six regions showing changes in glutamate uptake are presented in Table IV. The only significant change was a decrease in glutamate in the ventrolateral nucleus of the thalamus $(p<0.05$, paired $t$ test). No concomitant decrease in asparatate was seen in the same region.

\section{Discussion}

Electrophysiological and anatomical studies show that, in both carnivores and primates, pyramidal tract fibers give rise to branches ending in brain stem and spinal

TABLE II

Amino acid uptake in selected projection areas of pericruciate fibers in cat

Values were obtained as in Table I. Uptakes were determined at amino acid concentrations of $10^{-6} \mathrm{M}$. Values represent mean $\pm \mathrm{SEM}$ of determinations in four animals.

\begin{tabular}{|c|c|c|c|}
\hline Column A & Column B & Column C & Column D \\
\hline \multirow[t]{2}{*}{ Region } & Amino Acid & $\begin{array}{l}\text { Uptake on } \\
\text { Intact Side }^{\alpha}\end{array}$ & $\begin{array}{c}\text { Ratio: } \\
\text { Lesioned/ } \\
\text { Intact }\end{array}$ \\
\hline & \multicolumn{3}{|c|}{$\begin{array}{c}\mathrm{pmol} / 5 \mathrm{~min} / \mathrm{mg} \\
\text { protein }\end{array}$} \\
\hline \multirow[t]{2}{*}{ Caudate } & Alanine & $96 \pm 10$ & 0.99 \\
\hline & Tyrosine & $40 \pm 6$ & 1.00 \\
\hline \multirow[t]{2}{*}{ Ventrolateral thalamus } & GABA & $295 \pm 55$ & 0.92 \\
\hline & Glycine & $38 \pm 8$ & 0.86 \\
\hline \multirow[t]{2}{*}{ Red nucleus } & GABA & $119 \pm 11$ & 0.98 \\
\hline & Glycine & $43 \pm 25$ & 1.11 \\
\hline \multirow[t]{2}{*}{ Pons } & Alanine & $18 \pm 9$ & 0.62 \\
\hline & Tyrosine & $10 \pm 2$ & 1.60 \\
\hline \multirow[t]{2}{*}{ Cervical spinal cord } & GABA & $17 \pm 5$ & 0.76 \\
\hline & Glycine & $35 \pm 11$ & 0.93 \\
\hline \multirow[t]{2}{*}{ Lumbar spinal cord } & Alanine & $21 \pm 13$ & 1.12 \\
\hline & Tyrosine & $15 \pm 8$ & 0.70 \\
\hline
\end{tabular}

${ }^{a}$ Intact side is the side contralateral to cortical ablation.

TABLE III

Choline acetyltransferase (CAT) activity in projection areas of pericruciate fibers in cat

CAT activity was determined according to Fonnum (1975). Values represent mean \pm SEM for four animals.

\begin{tabular}{lcc}
\hline \multicolumn{1}{c}{ Region } & $\begin{array}{c}\text { CAT } \\
\text { Intact Side }\end{array}$ & $\begin{array}{c}\text { Ratio: } \\
\text { Lesioned/Intact }\end{array}$ \\
\hline & $\mu m o l / h r / g m$ & \\
Caudute & $17.7 \pm 1.6$ & 0.80 \\
Ventrolateral thalamus & $1.4 \pm 0.3$ & 1.07 \\
Pons & $1.6 \pm 0.4$ & 0.81 \\
Cervical spinal cord & $2.0 \pm 0.2$ & 0.90 \\
Lumbar spinal cord & $3.8 \pm 1.1$ & 0.60 \\
\hline
\end{tabular}

${ }^{a}$ Intact side is the side contralateral to cortical ablation. 
TABLE IV

Levels of six amino acids in selected brain areas after unilateral pericruciate cortex ablations

Amino acids were determined by high pressure liquid chromatography as described under "Materials and Methods." The values represent the mean \pm SEM of five animals.

\begin{tabular}{|c|c|c|c|c|c|c|}
\hline \multirow{2}{*}{ Region } & \multicolumn{6}{|c|}{ Amino Acid Concentrations } \\
\hline & Aspartate & Glutamate & Glutamine & Glycine & Taurine & GABA \\
\hline & \multicolumn{6}{|c|}{$\mu \mathrm{mol} / \mathrm{gm}$, wet weight } \\
\hline \multicolumn{7}{|l|}{ Caudate nucleus } \\
\hline Lesioned side & $2.09 \pm 0.40$ & $10.60 \pm 1.30$ & $8.20 \pm 0.80$ & $0.99 \pm 0.09$ & $2.08 \pm 0.46$ & $4.20 \pm 0.90$ \\
\hline Intact side & $2.20 \pm 0.50$ & $10.40 \pm 1.90$ & $8.10 \pm 0.80$ & $1.09 \pm 0.07$ & $2.04 \pm 0.50$ & $4.40 \pm 0.70$ \\
\hline \multicolumn{7}{|c|}{ Ventrolateral thalamus } \\
\hline Lesioned side & $2.70 \pm 0.80$ & $6.90 \pm 1.20^{a}$ & $5.70 \pm 0.80$ & $1.76 \pm 0.52$ & $1.91 \pm 0.40$ & $2.50 \pm 0.60$ \\
\hline Intact side & $2.90 \pm 0.70$ & $10.20 \pm 0.70$ & $6.20 \pm 0.60$ & $1.53 \pm 0.29$ & $1.87 \pm 0.34$ & $2.90 \pm 0.50$ \\
\hline \multicolumn{7}{|l|}{ Red nucleus } \\
\hline T.esioned side & $3.90 \pm 0.20$ & $5.90 \pm 0.60$ & $4.30 \pm 0.20$ & $2.06 \pm 0.29$ & $1.23 \pm 0.28$ & $2.90 \pm 0.70$ \\
\hline Intact side & $3.70 \pm 0.30$ & $6.30 \pm 0.50$ & $4.40 \pm 0.20$ & $2.08 \pm 0.53$ & $1.35 \pm 0.30$ & $3.80 \pm 0.70$ \\
\hline \multicolumn{7}{|l|}{ Pons } \\
\hline Lesioned side & $2.50 \pm 0.30$ & $6.20 \pm 0.70$ & $4.90 \pm 0.30$ & $1.53 \pm 0.33$ & $0.99 \pm 0.13$ & $1.66 \pm 1.00$ \\
\hline Intact side & $3.00 \pm 0.60$ & $6.10 \pm 0.80$ & $4.70 \pm 0.50$ & $1.61 \pm 0.38$ & $1.00 \pm 0.17$ & $1.53 \pm 0.87$ \\
\hline \multicolumn{7}{|c|}{ Cervical spinal cord } \\
\hline Lesioned side & $4.75 \pm 0.92$ & $6.50 \pm 1.20$ & $5.10 \pm 0.40$ & $5.01 \pm 1.05$ & $0.94 \pm 0.07$ & $2.40 \pm 0.30$ \\
\hline Intact side & $3.83 \pm 1.80$ & $6.60 \pm 1.40$ & $4.50 \pm 0.30$ & $5.42 \pm 0.57$ & $0.99 \pm 0.12$ & $2.00 \pm 0.30$ \\
\hline \multicolumn{7}{|c|}{ Lumbar spinal cord } \\
\hline Lesioned side & $3.49 \pm 0.94$ & $6.70 \pm 1.40$ & $4.90 \pm 0.30$ & $5.45 \pm 0.32$ & $0.79 \pm 0.08$ & $2.20 \pm 0.30$ \\
\hline Intact side & $3.79 \pm 0.83$ & $5.90 \pm 1.00$ & $5.00 \pm 0.10$ & $5.51 \pm 0.34$ & $0.83 \pm 0.15$ & $2.30 \pm 0.40$ \\
\hline
\end{tabular}

${ }^{a}$ Significantly different from lesioned side $(p<0.05$ by paired one-tailed $t$ test).

cord which have excitatory actions (Phillips and Porter, 1977; Endo et al., 1973). Fibers of cortical origin not traveling in the pyramidal tract also make excitatory connections in brain stem (Lawrence and Kuypers, 1968). In the primate, most pyramidal tract neurons arise from precentral areas 4 and 6 and the majority of the remaining ones arise from the parietal cortex. The origin of corticobulbar fibers not part of the pyramidal subset is similar (Phillips and Porter, 1977). Most of the pyramidal tract neurons in the cat originate in the pericruciate cortex as do the corticobulbar subset (Kuypers, 1958; Brodal, 1968).

In the present experiments, unilateral ablations destroyed the pericruciate cortex. We verified the effectiveness of our lesions and placement of our tissue punch sites by investigating the distribution of corticofugal fibers and axon terminals by a Fink-Heimer (1967) degeneration study in one cat. The distribution of degenerating cortical fibers and terminals is shown in Figure 1 and corresponds with results obtained by previous anatomical and electrophysiological investigations. The caudate nucleus receives a predominantly, but not exclusively, ipsilateral input from the pericruciate cortex (Kitai et al., 1976) and some of this input is from branches of the pyramidal tract (Endo et al., 1973). The pyramidal tract projects more prominently to ipsilateral ventrolateral nucleus of thalamus and to the ipsilateral red nucleus (Endo et al., 1973; Rinvik and Walberg, 1963). The pontine nuclei receive an ipsilateral input and the pontine tegmentum and the medullary reticular formation re- ceive a bilateral, but predominantly ipsilateral, pericruciate projection (Kuypers, 1958). The cortical fibers to the dorsal column nuclei, primarily the cuneate nucleus, leave the pyramidal tract and terminate bilaterally (Kuypers and Tuerk, 1964). The corticospinal projection is crossed (Kuypers, 1964; Endo et al., 1973). In each animal, our punch sites were located within the terminal distribution areas shown in Figure 1 and described above.

Electrophysiological studies investigating the excitatory neurotransmitter of corticofugal fibers have used iontophoretic technıques. Various iontophoretically applied agents have been screened for their ability to mimic the normal synaptic excitation of neurons by cortical and pyramidal stimulation. The most likely candidates were selected on the basis of the ability of iontophoretically applied blocking agents to counteract the postsynaptic excitation of both the naturally released presynaptic agent and the iontophoretic candidate. Application of these techniques to the study of neurons in the cerebral cortex (Stone, 1973, 1979), cuneate nucleus (Stone, 1976, 1979), and red nucleus (Altmann et al., 1976; Davis and Vaughan, 1969) excited by cortical or pyramidal tract stimulation showed that L-glutamate was a potent excitatory agent at all these sites. Acetylcholine was effective only at some sites but not in the red nucleus (Davis and Vaughan, 1969). L-Aspartate and DL-homocysteine also were found to be effective excitatory agents in some of the nuclei (Altmann et al., 1976; Davis and Vaughan, 1969; Stone, 1979). Drugs such as glutamate diethyl ester, 1-hydroxy-3-aminopyrrolidone-2 (HA-966), and DL-ami- 
noadipate blocked the excitation produced by cortical stimulation or iontophoretic application of some amino acids but were not selective enough in their antagonism to separate the excitatory synaptic effects of L-glutamate from L-aspartate (Altmann et al., 1976; Stone, 1979). Histochemical and neurochemical data on the levels of acetylcholine and its associated metabolic enzymes indicate low levels at sites where iontophoretically applied acetylcholine is ineffective (McLennan, 1969).

Recent biochemical studies have established a strong correlation between the selective high affinity synaptosomal uptake of certain amino acids and biogenic amines in tissue homogenates and the function of these compounds as neurotransmitters (Kuhar, 1973; Snyder et al., 1973). For many putative transmitters, however, additional markers of synaptic function are available, such as rate-limiting enzymes, levels, and transmitter-stimulated adenylate cyclase (Fonnum et al., 1977). For the excitatory amino acid L-glutamate, so called "high affinity uptake" has been shown to be associated with nerve terminals and is currently the best marker for putative glutamatergic fibers (Young et al., 1974; Walaas and Fonnum, 1979; Storm-Mathisen, 1977; McGeer et al., 1977). Even so, the uptake system is not entirely specific since glutamate and aspartate apparently compete for the same transport system (Balcar and Johnston, 1972; Snyder et al., 1973). By measuring glutamate uptake and amino acid concentrations, however, it has been possible to identify presumed glutamatergic neurons. These techniques have been used in the thalamus of the rat and show a reduction in high affinity uptake of $\mathrm{L}$-glutamate after loss of corticothalamic fibers following a cortical ablation (Fonnum, 1978). We have confirmed these data in the rat and have shown that similar changes occur in the red nucleus after sensorimotor cortical ablations. In thalamus, there is a selective decrease in the levels of glutamate but not of other putative amino acid neurotransmitters under the same conditions (Bromberg et al., 1980).

In the present study, we have found significant decreases in glutamate uptake in major projection areas of corticofugal fibers. The changes parallel the distribution of degenerating terminals following unilateral pericruciate destruction with the largest decrease $(44 \%)$ seen in ventrolateral thalamus ipsilateral to the lesion and smaller reductions in ipsilateral red nucleus $(36 \%)$, pontine nuclei $(20 \%)$, and caudate $(17 \%)$ nucleus. In the medulla, where the cortical inputs are bilateral, little change was seen. However, in spinal cord, where the corticospinal tract is completely crossed, there was decreased glutamate uptake on the side contralateral to the cortical lesion in the cervical $(37 \%)$ and lumbar $(24 \%)$ enlargements which are known to receive the majority of the corticospinal input. The caudate nucleus, which receives glutamatergic input from cortex (Divac et al., 1977; McGeer et al., 1977), may show only a small decrease in glutamate uptake in comparison to previous studies because our lesion was restricted to pericruciate cortex, whereas others have made complete hemidecortications (Divac et al., 1977; McGeer et al., 1977; Fonnum, 1978). Much of the presumed glutamatergic input to striatum comes from premotor and association cortex (Webster,
1961). Furthermore, some of the projection from cortex to striatum is crossed, thus making the side contralateral to the lesion an imperfect control. In our studies, despite significant changes in glutamate uptake, glutamate levels were only decreased $33 \%$ in the thalamus and no significant changes were seen in any amino acids in any other region. This failure to show changes in either glutamate or aspartate levels probably reflects the large size of the general metabolic pools of these amino acids in comparison to the neurotransmitter pool. In granuloprival hamster cerebellum, where glutamate uptake was decreased by $70 \%$, only a $43 \%$ decrease in glutamate levels were seen and this is an area of the brain in which probably the only glutamate terminals are those of the granule cells (Young et al., 1974). In the regions of the neuraxis studied here, there are likely to be several glutamatergic pathways independent of the corticospinal tract. Although the data definitely support the role of glutamate as a neurotransmitter of the corticothalamic tract, it is possible that the corticobulbar and corticospinal tracts use aspartate rather than glutamate as their neurotransmitter.

It is unlikely that the changes in glutamate are nonspecific. No changes in the uptake of four other amino acids were seen. These included two putative transmitters, GABA and glycine, and two nontransmitter amino acids, alanine (a neutral amino acid) and tyrosine (an aromatic amino acid).

Finally, the two other major excitatory neurotransmitters in the nervous system, substance $\mathbf{P}$ and acetylcholine, are unlikely to be the neurotransmitter of corticofugal fibers. Substance P is not found in cell bodies in layer V of cerebral cortex (Ljungdahl et al., 1978) and has no known projections paralleling the pyramidal tract. Similarly, cholinergic pathways are not distributed to these projection areas and we found no changes in CAT that paralleled the corticofugal pathways.

In summary, we present biochemical data which support the role of L-glutamate (or possibly L-aspartate) as the neurotransmitter(s) of corticofugal pathways. It will be important to investigate glutamate uptake, levels, and receptors in various models of regeneration as well as studies of spasticity and abnormal motor control. We also suggest that the development of clinically effective glutamate agonists and antagonists may allow important advances in the treatment of stroke and various conditions, such as cerebral palsy, multiple sclerosis, and amyotrophic lateral sclerosis which result in weakness, spasticity, and poverty of fine motor control.

\section{References}

Altmann, H., G. ten Bruggencate, P. Picklemann, and R. Steinberg (1976) Effects of glutamate, aspartate and two presumed antagonists on feline rubrospinal neurons. Pflugers Arch. 364: 249-255.

Balcar, V. J., and G. A. R. Johnston (1972) The structural specificity of the high affinity uptake of L-glutamate and Laspartate by rat brain slices. J. Neurochem. 19: 2657-2666.

Brodal, P. (1968) The corticopontine projection in the cat. I. Demonstration of a somatotopically organized projection from the primary sensorimotor cortex. Exp. Brain Res. 5: 210-234. 
Bromberg, M. B., J. B. Penney, Jr., A. B. Young, and B. S. Stephenson (1980) Evidence for glutamate as the neurotransmitter of corticothalamic and corticorubral pathways. Neurology (N. Y.) 30: 396.

Davis, R., and P. C. Vaughan (1969) Pharmacological properties of feline red nucleus. Int. J. Neuropharmacol. 8: 475-488.

Divac, I., F. Fonnum, and J. Storm-Mathisen (1977) High affinity uptake of glutamate in terminals of corticostriatal axons. Nature 266: 377-378.

Endo, K., T. Araki, and N. Yagi (1973) The distribution and pattern of axon branching of pyramidal tract cells. Brain Res. 57: 484-491.

Fink, R. P., and L. Heimer (1967) Two methods for selective impregnation of degenerating axons and their synaptic endings in the central nervous system. Brain Res. 4: 369-374.

Fisher, C. M., and H. B. Curry (1965) Pure motor hemiplegia of vascular origin. Arch. Neurol. 13: 30-44.

Fonnum, F. (1975) A rapid radiochemical method for the determination of choline acetyltransferase. J. Neurochem. 24: 407-409.

Fonnum, F. (1978) Comments on localization of neurotransmitters in the basal ganglia. In Amino Acids as Neurotransmitters, F. Fonnum, ed., pp. 143-153, Plenum Press, New York.

Fonnum, F., I. Walaas, and E. Iversen (1977) Localization of GABAergic, cholinergic and aminergic structures in the mesolimbic system. J. Neurochem. 29: 221-230.

Hodgin, J. C. (1979) The separation of pre-column o-phthaldialdehyde derivatized amino acids by high performance liquid chromatography. J. Liquid Chromatogr. 2: 1047-1059.

Kitai, S. T., J. D. Kocsis, and J. Wood (1976) Origin and characteristics of the corticocaudate afferents. An anatomical and electrophysiological study. Brain Res. 118: 137-141.

Kuhar, M. J. (1973) Neurotransmitter uptake: A tool in identifying neurotransmitter-specific pathways. Life Sci. 13: 16231634.

Kuypers, H. G. J. M. (1958) An anatomical analysis of corticobulbar connexions to the pons and lower brain stem in the cat. J. Anat. 42: 198-217.

Kuypers, H. G. J. M. (1964) The descending pathways to the spinal cord, their anatomy and function. In Organization of the Spinal Cord, J. C. Eccles and J. P. Schade, eds., pp. 178200, Elsevier Publishing Co., New York.

Kuypers, H. G. J. M., and J. D. Tuerk (1964) The distribution of the cortical fibres within the nuclei cuneatus and gracilis in the cat. J. Anat. 98: 143-162.

Lawrence, D. G., and H. G. J. M. Kuypers (1968) The functional organization of the motor system in the monkey. II. The effects of lesions of the descending brain-stem pathways. Brain 91: 15-36.

Lindroth, P., and K. Mopper (1979) High performance liquid chromatographic determination of subpicomole amounts of amino acids by precolumn fluorescence derivatization with $o$ phthaldialdehyde. Anal. Chem. 51: 1667-1674.

Ljungdahl, A., T. Hökfelt, and G. Nilsson (1978) Distribution of substance $P$-like immunoreactivity in the central nervous system of the rat. I. Cell bodies and nerve terminals. Neuroscience 3: 861-943.

Lowry, O. H., N. J. Rosebrough, A. L. Farr, and R. J. Randall (1951) Protein measurement with the Folin phenol reagent. J. Biol. Chem. 193: 265-275.

McGeer, P. L., E. G. McGeer, U. Scherer, and K. Singh (1977) A glutamatergic corticostriatal path? Brain Res. 128: 369373.

McLennan, H. (1969) Cholinesterase in the feline red nucleus. Int. J. Neuropharmacol. 8: 489-490.

Phillips, C. G., and R. Porter (1977) Corticospinal Neurones: Their Role in Movement, Academic Press, New York.

Ramon-Moliner, E. (1979) A retrothalamic system of collateral fibers from the cerebral peduncle. Brain Res. 170: 1-21.

Rinvik, E., and F. Walberg (1963) Demonstration of a somatotopically arranged corticorubral projection in the cat. J. Comp. Neurol. 120: 393-407.

Ropper, A. H., C. M. Fisher, and G. M. Kleinman (1979) Pyramidal infarction in the medulla-cause of pure motor hemiplegia sparing the face. Neurology (N. Y.) 29: 91-95.

Shapovalov, A. I. (1975) Neuronal organization and synaptic mechanisms of supraspinal motor control in the vertebrates. Rev. Physiol. Biochem. Pharmacol. 72: 1-54.

Snyder, S. H., W. J. Logan, J. P. Bennett, and A. Arregui (1973) Amino acids as central nervous transmitters: Biochemical studies. Neurosci. Res. 5: 131-157.

Stone, T. W. (1973) Cortical pyramidal tract interneurones and their sensitivity to L-glutamic acid. J. Physiol. (Lond.) 233: 211-225.

Stone, T. W. (1976) Blockade by amino acid antagonists of neuronal excitation mediated by the pyramidal tract. J. Physiol. (Lond.) 257: 187-198.

Stone, T. W. (1979) Amino acids as neurotransmitters of corticofugal neurones in the rat: A comparison of glutamate and aspartate. Br. J. Pharmacol. 67: 545-551.

Storm-Mathisen, J. (1977) Glutamic acid and excitatory nerve ending: Reduction of glutamic acid uptake after axotomy. Brain Res. 120: 379-386.

Walaas, I., and F. Fonnum (1979) The effects of surgical and chemical lesions on neurotransmitter candidates in the nucleus accumbens of the rat. Neuroscience 4: 209-216.

Webster, K. E. (1961) Cortico-striate interrelations in the albino rat. J. Anat. 95: 532-544.

Young, A. B., M. L. Oster-Granite, R. M. Herndon, and S. H. Snyder (1974) Glutamic acid: Selective depletion by viral induced granule cell loss in hamster cerebellum. Brain Res. 73: 1-13. 